\title{
NPI-Licensing and Focus Movement
}

\author{
Michael Wagner
}

MIT

\section{Focus Movement}

The exclusive 'only' can directly attach to the constituent it associates with, or it can associate with a constituent contained in the constituent it attaches to:

a. John played only baseball.

b. John only played baseball.

Theories of focus association differ with respect to whether or not the focused constituent in (1b) moves to associate with 'only'.

'Only' is a n operator that takes two arguments, a property $p(x)$ and a focus argument $f$. The proposition $p(f)$ is called the prejacent of a sentence involving 'only'. Only $(f)(p(x))$ presupposes the prejacent $p(f)$ and asserts that all propositions of the form $p(a)$ that are not already entailed by the prejacent are false, where $a$ is an element of the same semantic type as $f:{ }^{1}$

$$
\begin{aligned}
& \text { Meaning of 'only' }
\end{aligned}
$$

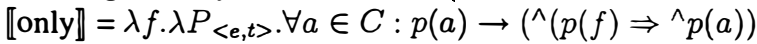

$$
\begin{aligned}
& \text { Presupposition: } p(f)
\end{aligned}
$$

(to be revised)

Following Rooth (1992), I assume C to be a contextual variable, which is filled in by a general pragmatic mechanism of restricting domains of quantification.

In this paper a syntactic argument in favor of focus movement for association with VP-only (e.g. 1b), contributing to earlier arguments in Tancredi (1990), Drubig (1994), Krifka (1996), Fox et al. (2001), Tancredi (2004), Krifka (2004). In particular, I propose that in the case of VP-only focus association involves covert movement of the focus constituent to the complement position of 'only'. Focus movement establishes the configuration necessary to interpret 'only': ${ }^{2}$

'Only' at LF

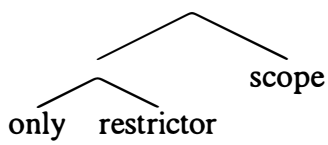

The alternative to focus movement is the in-situ theory which establishes the focus of VP-only without syntactic movement. In Rooth (1992) the focus of 'only' is determined by contextually restricting its quantification domain making use of the focus semantic value of its domain. The possibility of contextual domain restriction does not preclude focus movement, but it renders it unnecessary. 
Focus movement and in-situ association predict the same truth conditions, and can therefore only be distinguished by looking at syntactic evidence. Movement is island sensitive. But as is well known, focus association appears not to be affected by island constraints (Anderson 1972, Jackendoff 1972, Rooth 1985):

(4) a. You can do lots of things with bananas. I even know a guy who smokes them. (Anderson 1972, 897)

b. I don't know anyone who smokes bananas, I only know a guy who grows them.

Drubig (1994) presents evidence that in cases of association into islands, it is the entire island that contains the focus that moves: ${ }^{3}$

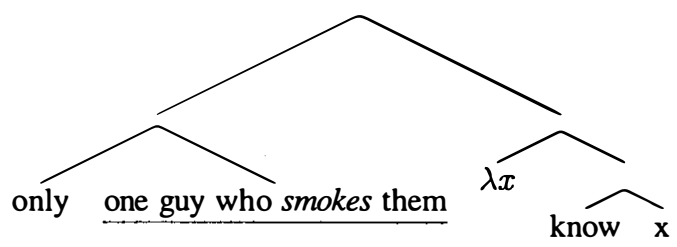

The distribution of NPIs discussed in this paper provides an argument for focus movement, and also for Drubig's claim that in cases of association into an island, the entire island containing the focus moves; similarly, in cases of association with a head, a constituent containing the head moves.

In the following, I will use underlining to mark the syntactic restrictor (i.e. the first argument) of 'only', and italics to mark the semantic focus. The scope of the only-phrase, that is, the second argument, will be $\ulcorner$ marked by corner symbols $?$ :

I only $\ulcorner$ know one guy who smokes them?

\section{NPI Licensing in the Scope of 'Only'}

\subsection{NPI Licensing and Strawson Entailment}

Klima $(1964,311)$ observes that negative polarity items are licensed by 'only':

(7) Only young writers $\ulcorner$ ever accept suggestions with any sincerity. $\urcorner$

NPIs are licensed in downward entailing (DE) environments (Ladusaw 1979).Consider 'every', which licenses NPIs in its restrictor but not in its scope:
a. * Every linguistics student $\ulcorner$ knows any famous linguist. $\urcorner$
b. Every student with any linguistic knowledge $\ulcorner$ knows McCawley?.

The distribution of NPIs correlates with downward-monotonicity. ${ }^{4}$ A DE environment allows to make inferences from supersets to subsets. 'Every' is DE in its first argument, where NPIs are licensed, but not in its second: 
(9) a. Every student $\ulcorner$ knows McCawley?.

$\rightarrow$ Every linguistics student $\ulcorner$ knows McCawley. $\urcorner$

b. Every student $\ulcorner$ knows a famous linguist. $\urcorner$ $\nrightarrow$ Every student $\ulcorner$ knows McCawley. $\urcorner$

Conversely, 'only' licenses NPIs in its scope, but not in its restrictor.

(10) NPI-licensing and 'only'

a. Only John $\ulcorner$ ate any kale?

b. * Only any students $\ulcorner$ ate kale $\urcorner$.

But 'only' is not DE in either argument (discussed e.g. in Atlas 1993, 1996):

a. Only John rate vegetables $\urcorner. \not$

Only John $\ulcorner$ ate kale $\urcorner$.

b. Only students $\ulcorner$ ate kale $\urcorner . \nrightarrow$

Only Linguistics students $\ulcorner$ ate kale $\urcorner$.

The account of NPI licensing in terms of DE-environments seems to break down. von Fintel (1999) observes that the inference to the subset in (11a) becomes valid if the presupposition of the conclusion is assumed to be true:

(12) a. Only John $\ulcorner$ ate vegetables $\urcorner$.

b. Presupposition: John ate kale

c. $\rightarrow$ Only $\underline{\text { John }}\ulcorner$ ate kale $\urcorner$.

As for (11b), however, even granting the presupposition of the conclusion does not lead to a valid inference to the subset in the first argument of 'only':
a. Only students $\ulcorner$ ate kale $\urcorner$
b. Presupposition: Linguistics students ate kale
c. $\quad \nrightarrow$ Only linguistics students $\ulcorner$ ate kale $?$.

von Fintel (1999) defines the notion Strawson-entailment to account for NPIlicensing: A Strawson-entails B if A entails B granted that the presuppositions and conventional implicatures of B satisfied. 'Only' is Downward-Strawson-Entailing (DSE) in the second but not in first argument-just where NPIs are licensed. DSE allows us to maintain the standard account of NPI licensing in terms of downward monotonicity. ${ }^{6}$

\subsection{NPIs and the Restrictor of 'Only'}

The approach based on Strawson-entailment predicts that NPIs should be licensed within all parts of a sentence containing 'only' that are not the focus that 'only' associates with. This, however, turns out to be wrong: 
(14) All the advisors were at the ceremony.

*Only anyone's parents $\ulcorner$ didn't show up at the graduation. $\urcorner$

When 'only' attaches to a DP, no NPIs are licensed within it, even in those parts of the NP that are not part of the focus. Consider also the following examples:
a. * Only any inhabitant of Twin Earth $\ulcorner$ met Particle Man $\urcorner$
b. * Only an author of any comic $\ulcorner$ met Particle Man?.
c. Only an inhabitant of Twin Earth $\ulcorner$ met any alien?.

The restrictor of 'only' is generally not DSE, as was shown above. However, the environments that are not part of the focus in (15) actually do seem to allow inferences from super-sets to subsets, so NPIs are expected to be licensed:
a. Only an inhabitant of Twin Earth $\ulcorner$ met Particle Man?.
b. Presupposition: A female inhabitant of Twin Earth met Particle Man.
c. $\rightarrow$ Only a female inhabitant of Twin Earth $\ulcorner$ met Particle Man?

This suggests that the presupposition that 'only' introduces is actually weaker than assumed so far. I propose that it is only an existential statement. What is abstracted over is not the semantic focus of 'only' but its syntactic restrictor:'

(17) Presupposition of 'only' (Revised from (2)): $\exists x . x$ met Particle Man.

Assuming (17), the downward inference is indeed no longer warranted:

(18) a. Only an inhabitant of Twin Earth $\ulcorner$ met Particle Man?.

b. Presupposition: $\exists x . x$ met Particle Man.

c. $\quad$ Only a female inhabitant of Twin Earth $\ulcorner$ met Particle Man $\urcorner$.

NPIs are not licensed in the syntactic restrictor of 'only' ${ }^{8}$ The fact that NPIs cannot be licensed in the unfocused part of the DP-only attaches to suggests that the entire $D P$ is in fact the restrictor. The key to understanding the distribution of NPIs is to distinguish between the syntactic restrictor of 'only' and the semantic focus, following Jacobs (1983). The remaining question is then how the semantic focus 'only' associates with can be smaller than its restrictor as in (15).

In the case of DP-only, altematives to the entire DP are considered. The correct semantic focus can be obtained by a further contextual domain restriction. One way to achieve this restriction and resolve the mismatch between syntactic and semantic focus is the presuppositional altematives theory outlined in Rooth (1992). This move to combine domain restriction with a movement theory was proposed in Krifka (1996), Kiss (1998), Krifka (2004). The following alternative sets have to be made contextually relevant in order to achieve narrow focus in (15):

(19) a. ALT (an inhabitant of Twin Earth) = an inhabitant of Twin Earth, an inhabitant of Earth, an inhabitant of Mars, ... 
b. ALT (an author of comics) = an author of a comic, a reader of a comic,

The presupposition that narrow focus on 'Twin Earth' imposes on the context is that there must be an antecedent of the shape 'an inhabitant of $x$ '. This presupposition together with the presupposition introduced by 'only' is still not sufficient to render DSE, and NPIs are correctly ruled out:
a. Only an author of comics $\ulcorner$ met Particle Man $\urcorner$.
b. Only-Presupposition: $\exists x . x$ met Particle Man.
c. Focus-Presupposition: There is an antecedent of shape 'an inhabitant of $x^{\prime}$.
d. $\quad \nrightarrow$ Only an author of super-hero comics $\ulcorner$ met Particle Man $\urcorner$.

The current proposal makes the additional prediction that there is no direct association between 'only' and prosodic focus. Prosodic focus marking introduces the presupposition that certain antecedents are available in the context. 'Only' can take a restrictor that contains prosodic focus marking, but this need not mean that only alternatives of the relevant shape are considered. ${ }^{9}$ The following example illustrates that the semantic focus can be bigger than just the accented constituent:

(21) Many students in the program are in trouble because of the language requirement, even though they know some foreign language. The requirement explicitly calls for knowledge of Latin.

Jim only knows Ancient Greek. So he was told to either drop out or take Latin classes. And he's not the only one who is in trouble.

a. Mary only knows Modern Greek.
b. \# Mary only knows Modern Greek.

So she's got the same problem. She'll have to learn Latin.

The prosody on 'Modem Greek' in (a) signals that there is a contrasting antecedent 'Ancient Greek' in the discourse; it does not rule out considering 'Latin' as an alternative in evaluating the meaning of 'only'. Consider also:

(22) In order to pass this class, you had to present in class or at least review one of the readings, and you had to write a final squib.

Bill only reviewed one of the readings. So he didn't pass, since he didn't write the final paper. And he's not the only one who failed.

a. Mary only presented one of the readings.

b. \#? Mary only presented one of the readings.

So she also didn't pass, since she didn't write the final paper.

Further evidence that association of 'only' with prosodic focus is only indirect is discussed in Schwarzschild (2004). ${ }^{10}$ 


\section{An Argument for Focus Movement}

'Only' licenses NPIs in its scope, but not in its restrictor. The distribution of NPIs can be used to establish which constituents are part of the restrictor or part of the scope of 'only' respectively, and provides an argument for focus movement.

\subsection{NPI Licensing and VP-only}

The in-situ theory interprets association with VP-only without focus movement. von Fintel $(1999,31)$ reports (and credits Danny Fox for raising the issue) that NPIs are licensed in the unfocused part of a VP that 'only' attaches to:

(23) There only was any precipitation in Medford.

This stands in sharp contrast to the case of DP-only observed above, where NPIs are not licensed in the unfocused parts of the DP. Consider also:

(24) a. John only gave any kale to his friends.

b. John only gave kale to any of his friends.

The restrictor of 'only' cannot be the entire VP, otherwise the NPIs should not be licensed. The solution proposed here is that (23) and (24) involve focus movement of the associating DPs to the complement position of 'only':"11

a. John only $\ulcorner$ gave any kale to his friends?.

b. John only $\ulcorner$ gave kale to any of his friends?

Focus movement provides the first argument for 'only' at LF:

a. [ only his friends ] [ $\lambda \mathrm{x}$. John gave any kale to $\mathrm{x}$ ].

b. [ only kale ] [ $\lambda \mathrm{x}$. John gave $\mathrm{x}$ to any of his friends].

The first piece of evidence that focus movement obeys constraints on movement is that in the double object construction NPI licensing is more restricted than in the dative construction. Bruening (2001) observes that in double object constructions, the scope between the indirect and direct object is frozen (27a), as opposed to the dative construction, where both scopes are available (27b)

a. I gave a child each doll.

b. I gave a doll to each child

$$
\begin{array}{r}
a>\text { each },{ }^{*} \text { each }>a \\
a>\text { each }, \text { each }>a
\end{array}
$$

The prediction is now that associating with the second argument in the DOconstruction does not license a DP in the first argument. This is bome out:

a. She only ' gave her student any funding. $?$

b. * She only ' gave any student summer funding. $?$

Given the distribution of NPIs in the case of DP-only, the fact that VP-only licenses NPIs in the non-focal part of the VP is evidence for focus movement. The doubleobject restriction is a first piece of evidence that regular constraints on movement apply. The next two sections present evidence that in cases where the actual focus cannot move on its own, a constituent containing the focus moves. ${ }^{12}$ 


\subsection{The Head Restriction}

There is no $\bar{A}$-Head-Movement. The only way to focus-move a head is to move a bigger constituent that contains the head. The following generalization should hold:

(29) Prediction I: The Head Restriction

If 'only' associates with the head of a constituent, it does not license NPIs in the complement of the head.

Association with a transitive predicate does not license an NPI in its complement:

(30) While John was willing to help cooking the vegetables, he was a bit particular about which chore he was going to be assigned.
a. * John only $\ulcorner$ cut any vegetables?
b. John didn't cut any vegetables.

I am using sentential negation as a base-line for NPI-licensing, since it licenses NPIs in its scope irrespective of the shift in focus. This sentence should be grammatical if 'ate' is the focus of 'only', and 'any vegetables' is in the scope of 'only', that is, if the LF of the sentence in (30) looked as follows:

(31) [ only cut ] [ $\lambda \mathrm{x}$. John $\mathrm{x}$ any vegetables]

The position of the direct object should be DSE:

(32) a. John only ATE vegetables.

b. Presupposition: John did something with kale.

c. $\rightarrow$ John only ATE kale.

Applying the same logic as in the case of DP-only, the facts can be explained if we take the entire VP to be the restrictor of 'only' in this example:

(33) [ only cut vegetables ] [ $\lambda \mathrm{x}$. John $\mathrm{x}]$

The DO is part of the restrictor of 'only', therefore NPIs are not licensed. ${ }^{13}$ Prediction (29) is further confirmed by focus association with heads other than the verb:

(34) There are several parks in this city, and one is allowed to drive through, but only at $10 \mathrm{mph}$. I wonder whether John always went through the parks, or whether he sometimes went around any park.
a. * John only $\ulcorner$ drove through any park?.
b. John didn't drive around any park.

Association with the preposition in (34) does not license an NPI inside of the PP. A similar observation can be made for association with complementizers:

Did she tell you at what time we will arrive? 
a. * She didn't tell me when anyone will arrive. She only $\ulcorner$ told me that anyone will arrive?

b. She didn't tell me when anyone will arrive. In fact, she didn't tell me that anyone will arrive.

NPIs within a relative clause are not licensed by association with its head:
a. * She only $\ulcorner$ went to $\underline{a}$ talk that was given by any student?
b. She didn't go to a talk that was given by any student.

The final example involves association with the head of a DP that includes a possessor. The contrast between $(37 a, b)$ illustrates the point:

a. * Anna only 'knew anyone's parents? , but she didn't know any of the other guests at the commencement.

b. Anna didn't know anyone's parents, but she knew all the other guest at the commencement.

The contrast between (34) through (37) on the one hand, where NPIs within the VP are not licensed, and (24) on the other, where NPIs within the VP are licensed, cannot be explained by the in-situ theory of focus association. All of these facts immediately follow if there is focus movement, and if focus movement is XP-movement. Association with a head involves movement of an XP that contains the head. ${ }^{14}$

\subsection{The Island Restriction}

Movement is island sensitive. Association into islands, however, is rather freely allowed (Anderson 1972), as was illustrated in (4), a fact often taken to speak against the movement approach to focus association.

Drubig (1994) offers a way to rescue the movement theory of focus association by proposing that in cases where an operator associates into an island, the entire island moves. If this hypothesis is correct, then the entire island should be the restrictor of 'only', not just the semantic focus. The prediction is that NPIs are not licensed anywhere in the island:

(38) Prediction II: Island Restriction

Association with a constituent within an island cannot license an NPI in the same island.

A complication regarding the distribution of NPIs in islands needs to be taken into account in testing this. The following contrast seemingly supports (38):

a. ? I only $\ulcorner$ saw offprints of any pictures of John ?.

b. * I only `saw those offprints of any pictures of John ?.

This looks like a typical specificity effect, as it is observed for wh-extraction: 
(40) a. Who did you see pictures of $t$ ?

b. ?* Who did you see the pictures of $t$ ?

But definite descriptions even block NPI licensing by sentential negation:

(41) a. I didn't see offprints of any pictures of John.

b. * I didn't see those offprints of any pictures of John.

In general, however, sentential negation licenses NPIs into an island. NPIs in subject position are licensed under sentential negation, as observed in (May 1985): ${ }^{15}$

(42) a. Philby doesn't believe that anyone suspects Burgess.

b. Philby doesn't believe anyone suspects Burgess.

This is surprising if the 'any-phrase' really has to undergo phrasal movement, since it would be movement from an island. Evidence against phrasal covert movement out of islands is discussed in Guerzoni (2004). Guerzoni (2004) proposes instead that NPIs are licensed within islands exactly when no logical operator is intervening, following Linebarger (1980).

The important observation for the present discussion is the following: NPIs are licensed in islands under negation only if there is no logical operator intervening. In order to test whether association into islands can license NPIs within the same island, we therefore have to make sure no logical operator intervenes. We are now in a position to construct test cases for the prediction in (38).

The following example illustrates that associating with a constituent within a relative clause does not license NPIs anywhere else in the same island:

(43) a. Yesterday during the dinner we talked about the restaurants we had been to, and who had recommended them to us. Mary was very negative about many places. I don't mind that she's very picky about restaurants, but $i$ think she was just trying to flatter John. She never complained about a restaurant that John had recommended to anyone.

b. Yesterday during the dinner we talked about the restaurants we had been to, and who had recommended them to us. Mary, as usual, seized the opportunity to annoy John. *?She only $\ulcorner$ complained about a restaurant that John had recommended to anyone. ?

The next example is based on because-clauses. Because-clauses constitute islands of extraction. For example, scope taking movement from the because-clause is impossible. The prediction is now that association into the because-clause does not license NPIs within the because-clause:

*Mary only `gave a book to John because Bill gave any book to him?

As predicted, focus association into an island does not license NPIs within the same island. The explanation for the island restriction is the same as that for the head restriction: The entire island moves, and becomes the restrictor of 'only': 


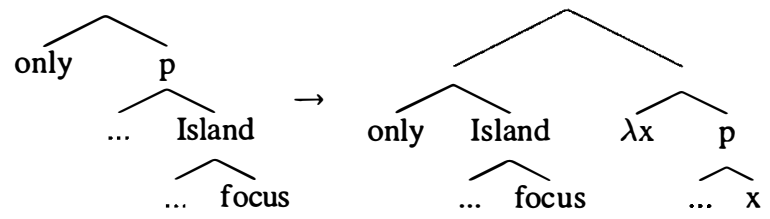

A further prediction is then that NPIs should be licensed in the parts of the VP below 'only' that do not pertain to the because-clause. This is indeed correct:

(46) She only gave anything to anyone because you did.

(cf. Linebarger (1980) and Beaver and Clark (2002) below for similar examples)

The movement theory explains the difference between (44) and (46). A theory that predicts licensing in the non-focal parts under 'only' fails to make this distinction. One such theory is the one proposed in Beaver and Clark (2002), a theory designed to explain why NPIs can't be the focus of 'only', but can appear in the non-focal part of the sentence.
a. She only rbudged an inch?
(literal reading only, i.e. NPI is not licensed (cf. Beaver (2004)))
b. * She only $\ulcorner$ payed any attention. $\urcorner$

All instances of NPI licensed by VP-only in the unfocused part of the sentence reported in Beaver and Clark (2002) involve constructions in which focus movement can derive a configuration in which [ only + focus-constituent ] c-commands the NPI. None of the examples involve NPIs that are trapped with the focus in an island. The data is thus compatible with the focus movement theory: ${ }^{16}$

a. I only $\ulcorner$ ever had cream of mushroom?

b. The central problem is that it is only rever possible to sample a child's language over a fuxed period of time and within a finite number of situations?

c. Because we found one order of this group to be much more likely than any other, we probably only $\ulcorner$ care to see the map distances for this single order?

d. The timing belt should be changed at 60000 miles OR 60 months, and most people only $\ulcorner$ bother with the mileage?

e. Like rintintin you only $\ulcorner$ give a shit for $\underline{m e}\urcorner$.

f. ...if the left flipper is too weak for a bearkick, as it often is because people who run arcades are usually assholes and only $\ulcorner$ give a shit about their street fighter shit games?, use that left flipper to send the ball back into the swamp. 
g. Well, I certainly don't give a damn. I only $\ulcorner$ gave a damn because I thought you did?

h. If you were a kid in Cleveland, you only $\ulcorner$ gave a damn about two things-the Beatles and Ghoulardi $\urcorner$.

i. Stuard David, visionary and poet, cursed it before trying it, and would only `lift a finger to pick his nose or write a book. $\urcorner$

j. They're vicious, greedy, buggers who'd only 'lift a finger to save their best friend if they thought they'd profit from it. '

This section presented evidence for the claim that focus movement is island sensitive. The observed distribution of NPIs is predicted by the theory defended here, but remains unaccounted for within the in-situ theory of focus association.

\section{Why Move?}

The particular movement analysis here conflicts with the analysis in Rooth (1996), who presents evidence for island-insensitive focus movement. The data comes from multiple focus constructions, where two foci are inside the same island, but associate with different focus operators: ${ }^{17}$

(49) We only recovered the diary entries that Marylin made about John. We also only $_{2}$ recovered the diary entries that Marylin $_{2}$ made about Bobby .

According to the theory presented here, focus movement from islands i impossible. One reason not to invoke movement for (49) is that extraction from under only is usually impossible (Beaver 2004). The correct focus constituent for the higher focus operator given the assumptions here must be the entire only-phrase then:

(50) a. Domain, Focus-Constituent, and Focus for 'only':

They also only $\ulcorner$ found the diary entries that Marylin made about Bobby?

b. Domain, Focus-Constituent, and Focus for 'also':

They also $\ulcorner$ only found the diary entries that Marylin made about Bobby?

How is the correct focus association achieved without movement? I see two potential solutions to determining the focus of each focus adverb. One possible move is to index foci as proposed in Kratzer (1991), Wold (1996). The presuppositional skeleton used to evaluate each focus operator consists of the constituent it attaches to with the co-indexed (and only the co-indexed) foci replaced by variables. A second possibility is to freely allow contextual domain restriction to settle the actual focus for each operator. This disconnects prosodic focus from the domain restriction of 'only', a move was argued for independently based on examples (21) and (22). This is also the position of Schwarzschild (2004). 
Either solution raises the following question: if contextual domain restriction or indexation of foci can render the correct semantic focus where movement is impossible, then why move in the cases where movement is possible?

I propose that the reason for focus movement is the following: focus movement renders the presupposition that 'only' introduces stronger. The principle at play is 'Maximize Presupposition' from Heim (1991). Consider the presupposition for association with a direct object, depending on whether or not focus movement is involved. The presupposition in (b) entails the one in (a), but not vice-versa, i.e. focus movement renders a stronger presupposition:
a. No Movement: John only 「played baseball ? Presupposition: $\exists x$. John x-ed.
b. Focus Movement: John only 'played baseball? Presupposition: $\exists x$. John played $\mathrm{x}$.

Focus movement is thus not triggered by a focus feature that is placed on the actual semantic focus. Disconnecting focus movement from the focus contained within the moved constituent is also argued for in Horvath (2000). In the proposal here there is no syntactic trigger for focus movement at all.

This approach has the additional benefit that moving a constituent that contains a focus is not an instance of pied-piping (as in Drubig (1994)). Horvath (2000) observes that pied-piping is usually only triggered by either heads or specifiers, and concludes that focus movement cannot be a case of pied-piping. Focus movement even occurs when the focus is deeply embedded in a syntactic island, and thus does not show the typical properties of pied-piping. ${ }^{18}$

\section{Other Focus Operators}

'Only' seems to differ from other focus-sensitive operators such as 'just' in whether or not movement is involved. Consider the following contrast:

(52) a. She only gave any funding to her students.

b. ?? She just gave any funding to her students.

This correlates with the fact that the syntactic distribution of 'just' is different, e.g. there is no DP-just. Replacive negation (Jacobs 1982, 1991) on the other hand seems to associate by movement. Replacive negation is a focus sensitive operator that licenses NPIs in its restrictor, but not in its scope:

(53) a. Not any inhabitant of Earth but an inhabitant of Twin Earth $\ulcorner$ met Particle Man?.

b. Not an author of any comic but a reader of some comic $\ulcorner$ met Particle Man?.

c. * Not Particle Man but Universe Man $\ulcorner$ met any inhabitant of Twin Earth yesterday? 
This is the converse pattern with respect to NPI licensing compared to 'only'. The phrases [ only + focus-constituent ] and [ replacive neg + focus-constituent ] have opposite monotonicity properties, which is further confirmed by the test from Barwise and Cooper $(1981,193)$ and $\operatorname{Hom}(1996,10)$ who note that quantifiers with the same monotonicity combine with and, whereas quantifiers with opposite monotonicity combine with but:

(54) Not the entire family but only John showed up at the graduation.

Consider now association of replacive negation with because-clauses:

a. * Mary didn't $\ulcorner$ give anything to anyone because Anna did, but because John did ?.

b. Mary didn't $\ulcorner$ gave a book to John because anyone else did, but because she wanted to?.

Since because-clauses are islands, one prediction for replacive negation is that association into an island should license an NPI in the same island, even the non-focal part, because it will move and end up in the restrictor. This prediction is borne out:

(56) Mary didn't ' give a book to John because Bill gave any book to him? because Anna did.

A closer look at other differences between focus operators observed in Beaver and Clark (2003) would be needed to further explore the validity of focus movement.

\section{Conclusion}

The distributional pattern of NPIs under VP-only can be captured by a movement theory of focus association, but seems incompatible with an in-situ approach.

\section{Endnotes}

*Thanks to Kai von Fintel and Danny Fox for help and guidance in developing the argument. I am also indebted to comments by 3 anonymous reviewers for SALT and by Pranav Anand, David Beaver, Daniel Büring, Jon Gajewski, Elena Guerzoni, Irene Heim, Julia Horvath, Manfred Krifka, Mats Rooth, Roger Schwarzschild, Tim Stowell, Yael Sharvit, Anna Szabolcsi, Satoshi Tomioka, the audience at the MIT LF-Reading Group in January 2004, at the workshop on focus and intonation at UMass Amherst in May 2004, at Console XII in Troms $\varnothing$ in December 2004, and at SALT XV. All errors are my own.

${ }^{1}$ Whether the truth of the prejacent is part of the assertion (Kuroda 1969, Lakoff 1970, Taglicht 1984), a presupposition (Horn 1969), or a conventional implicature (Karttunen and Peters 1978, Ippolito 2005) is still controversial. I assume for the time being that the truth of the prejacent is presupposed. 
${ }^{2}$ That focused constituents move covertly was proposed already in Chomsky (1976, 344). For an approach employing overt focus movement see Kayne (1998). I will not discuss the possibility approach based on overt movement in this paper.

3Actually, the restrictor becomes a specifier of 'only' in Drubig's approach, and not its complement, just as in the proposal in Tancredi (1990). This is compatible with the proposal here. But it would require putting the $\lambda$-abstraction to be below 'only', i.e. it would not be placed directly below the landing site, as is usually assumed. This analysis is proposed in Lee $(2005,177)$. I chose movement to the complement position of 'only' because it avoids making this stipulation, and it keeps the LFconfiguration for 'only' uniform for DP-only and VP-only.

${ }^{4} \mathrm{NPIs}$ have to be licensed by a c-commanding DE-operator. As we will see, it is not sufficient for an NPI to be in an environment that happens to be downward entailing because of the particular context that is considered. In order for NPIs to be licensed, they have be c-commanded by a DE-operator.

5 'Every' and 'only' have mirror image patterns with respect to NPI-licensing. They differ furthermore in that 'every' is a determiner, whereas 'only' is not:
a. * Every the student knew him.
b. Only/all the students knew him.

'All' provides thus the more minimal comparison, since it is also not a determiner. That 'only' is not a determiner is supported by the fact that it is not a conservative operator, and according to Barwise and Cooper (1981) all natural language determiners are conservative.

${ }^{6}$ Klooster (1998) proposes hidden negations in all cases in which NPIs are licensed but downward monotonicity is not satisfied, and argues against the downwardmonotonicity view of NPI-licensing. I do not have the space to consider alternative approaches to NPI-licensing in this paper.

${ }^{7}$ Following Rooth (1999) and contrary to Geurts and van der Sandt (2004) I assume that focus alone does not introduce an existential presupposition, and the presupposition used here is lexically triggered by 'only'. This assumption, however, is not crucial for the present proposal.

${ }^{8}$ There are apparent exceptions to this generalization, where NPIs seem to be licensed in the scope of 'only'. However, these cases invariably involve NPIs that are licensed by operators other than 'only' (the same point is made in Hom (1996, 27ff), von Fintel (1999), and Beaver and Clark (2002)):
a. Negation:
Only that John didn't bring any present $\ulcorner$ was surprising $\urcorner$.
b. Generic/Universal Operator in Law-like statements
Only anyone from Paris $\ulcorner$ would have known about this place $\urcorner$.

These NPIs are also licensed even when 'only' is omitted, and they are thus irrelevant for the present discussion:

a. That John didn't bring any present was surprising. 
b. Anyone from Paris would have known about this place.

${ }^{9}$ The same prediction is tacitly made by the approach based on F-marking and Focus Projection in Büring (to appear). I do not assume F-marking or Focus-projection here. For a discussion of the issues involved compare Wagner (2005).

${ }^{10}$ von Fintel (1994) and Beaver and Clark (2003) show that the focus of 'only' has to contain some level of prominence and is incompatible e.g. with clitics. This is a potential problem for the indirect theory of association with focus proposed here.

${ }^{11}$ I assume that in cases where 'only' associates with both arguments, either they stay in-situ, or they move as a constituent, as proposed in Tancredi (1990).

${ }^{12}$ Daniel Büring pointed out to me that NPIs do not appear to be licensed by VP-only in adjuncts. The relevant examples involve VP-adjuncts:

(60) ?? She only 「 met John on any weekday?.

This would be expected only if the adjunct attaches higher than 'only', which would require a 'right-ascending' analysis of VP-adjuncts. Arguments against such a right-ascending view of VP-modifiers are presented, however, in Larson (2005, and references therein). I have to leave this as an open issue, further investigation of this data would be necessary.

${ }^{13}$ Jon Gajewski (p.c.) asks why the direct object cannot evacuate the VP, and the remnant VP subsequently associate with 'only'. I have no way of ruling this out.

${ }^{14}$ Roger Schwarzschild (p.c.) raised the question why there is no focus movement for DP-only. But focus movement to DP-only would not lead to an interpretable configuration. The second argument of 'only' must be a property, and applying the first argument to it must yield a truth value. Applying the first argument to the second argument after focus movement in DP-only would not yield a truth value but a value of the type of the DP, e.g. an individual if the DP is a referring expression.

15 'Believe' is potentially a problematic example since it is a 'Neg-raising' predicate. Licensing is also possible under 'say' or 'claim'.

${ }^{16}$ The example in $(48 \mathrm{~g})$ poses a challenge: While the NPI in the antecedent for the VP ellipsis is in an environment that is predicted to be DSE, an NPI would not be licensed in the ellipsis site. But maybe the VP in the ellipsis site is not formally identical to the antecedent, but only semantically, and really includes the indefinite 'someone'. In fact, Sag $(1976,157 \mathrm{ff})$ uses precisely this kind of evidence to argue that ellipsis does not require linguistic identity, but only semantic equivalence.

${ }^{17} \mathrm{Krifka}$ (2004) argues that in this particular example the 'about'-phrase is in fact not inside of the island, but attaches to the higher proposition as a topic phrase ('about Bobby, ...'). But the following example does not have the same attachment ambiguity, but is acceptable:

(61) Of all rumors about JFK, they only confirmed the claim that Marylin had an affair with him. They also only $_{2}$ confirmed the claim that Marylin 2 had an affair with $B o b b y_{1}$.

Multiple association into islands with different focus operators is possible. 
${ }^{18}$ Daniel Büring and Yael Sharvit point out a problem, namely the interaction between focus movement and scope. Consider the following example:

(62) She only $\ulcorner$ wanted to kiss at most 3 students?

Why is it that association with focus does not seem to force wide scope of the quantifier over the intensional verb? In order to account for this, I have to assume that the correct scope readings can be accounted for by either semantic or syntactic reconstruction of focus movement.

\section{References}

Anderson, Stephen R.: 1972, 'How to get 'even", Language 48, 893-906.

Atlas, Jay David: 1993, 'The Importance of being "only": Testing the Neo-Gricean versus Neo-Entailment Paradigms', Journal of Semantics 10, 301-318.

Atlas, Jay David: 1996, “Only' Noun Phrases, Pseudo-Negative Generalized Quantifiers, Negative Polarity Items, and Monotonicity', Journal of Semantics 13, 265-328.

Barwise, Jon and Robin Cooper: 1981, 'Generalized Quantifiers and Natural Language', Linguistics and Philosophy 4, 159-219.

Beaver, David I.: 2004, 'Five Only Pieces', Theoretical Linguistics 30, 45-64.

Beaver, David I. and Brady Z. Clark: 2002, 'Monotonicity and Focus Sensitivity', in B. Jackson (ed.), Proceedings of SALT XII. CLC Publications, Cornell.

Beaver, David I. and Brady Z. Clark: 2003, "'Always" and "Only": Why not all focus sensitive operators are alike'. Ms. Stanford University.

Bruening, Benjamin: 2001, 'QR Obeys Superiority: Frozen Scope and ACD', Linguistic Inquiry 32, 233-273.

Büring, Daniel: to appear, 'Focus Projection and Default Prominence', in V. Molnár and S. Winkler (eds.), Proceedings from the Symposium 'Informationsstruktur -Kontrastiv' (working title). Mouton De Gruyter.

Chomsky, Noam: 1976, 'Conditions on Rules of Grammar', Linguistic Analysis 2, 303-351.

Drubig, Hans Bernhard: 1994, 'Island Constraints and the Syntactic Nature of Focus and Association with Focus', in Arbeitspapiere des Sonderforschungsbereichs 340: Sprachtheoretische Grundlagen der Computerlinguistik, Vol. 51. Tübingen/Stuttgart.

von Fintel, Kai: 1994, Restrictions on Quantifier Domains, PhD dissertation, University of Massachussetts, Amerhst.

von Fintel, Kai: 1999, 'NPI Licensing, Strawson Entailment, and Context Dependency', Journal of Semantics 16, 97-148.

Fox, Danny, Jon Nissenbaum, and Uli Sauerland: 2001, 'Association with Focus'. Lecture Notes, MIT.

Geurts, Bart and Rob van der Sandt: 2004, 'Interpreting focus', Theoretical Linguistics 30, 1-44. 
Guerzoni, Elena: 2004, 'Intervention Effects on NPIs and Feature Movement: Towards a unified account of intervention'. MIT.

Heim, Irene: 1991, 'Artikel und Definitheit', In von Stechow and Wunderlich (1991), 487-535.

Horn, Larry R.: 1969, 'A Presuppositional Analysis of Only and Even', CLS 4.

Horn, Larry R.: 1996, 'Exclusive Company: Only and the Dynamics of Vertical Inference', Journal of Semantics 13, 1-40.

Horvath, Julia: 2000, 'Interfaces vs. the Computational System in the Syntax of Focus', in H. Bennis, M. Everaert, and E. Reuland (eds.), Interface Strategies, 183-206. Royahl Netherlands Academy of Arts and Sciences, Amsterdam.

Ippolito, Michela: 2005, 'The Only Implicature'. Presented at the LSA Meeting, Oakland.

Jackendoff, Ray S.: 1972, Semantic Interpretation in Generative Grammar. MIT Press, Cambridge, Ma.

Jacobs, Joachim: 1982, Syntax und Semantik der Negation im Deutschen. Wilhelm Fink Verlag, München.

Jacobs, Joachim: 1983, Fokus und Skalen. Zur Syntax und Semantik der Gradpartikel im Deutschen. Niemeyer, Tübingen.

Jacobs, Joachim: 1991, 'Negation', In von Stechow and Wunderlich (1991).

Karttunen, Lauri and Stanley Peters: 1978, 'Conventional Implicature', in D. Dinneen and C.-K. Oh (eds.), Syntax and Semantics II: Presupposition.

Kayne, Richard S.: 1998, 'Overt vs. Covert Movement', Syntax 2, 128-191.

Kiss, Katalin É.: 1998, 'Identification Focus and Information focus', Language 74, 245-273.

Klima, Edward S.: 1964, 'Negation in English', in J. Fodor and J. Katz (eds.), The structure of language: readings in the philosophy of language, 246-323. Prentice Hall, Englewood Cliffs, NJ.

Klooster, Wim: 1998, 'Monotonicity and Scope of Negation'. Ms. HIL/UvA.

Kratzer, Angelika: 1991, 'The Representation of Focus', In von Stechow and Wunderlich (1991), 825-834.

Krifka, Manfred: 1996, 'Frameworks for the Representation of Focus', in Formal Grammar Conference. 8th European Summer School in Logic, Language, and information. Prague.

Krifka, Manfred: 2004, 'Association with Focus Phrases'. Ms. HumboldtUniversität.

Kuroda, S.-Y.: 1969, 'Attachment Transformations', in D. A. Reibel and S. Schane (eds.), Modern Studies in English. Prentice Hall, Englewood Cliffs, N.J.

Ladusaw, William A.: 1979, Polarity Sensitivity as Inherent Scope Relations, PhD dissertation, University of Texas at Austin. Distributed by IULC, 1980.

Lakoff, George: 1970, 'Repartee, or a Reply to 'Negation, Conjunction, and Quantifiers", Foundations of Language 6, 389-422.

Lappin, Shalom (ed.): 1996, The Handbook of Contemporary Semantic Theory. Blackwell, London.

Larson, Richard K.: 2005, 'Sentence Final Adverbs and Scope', in K. Moulton and M. Wolff (eds.), Proceedings of NELS 34. Stony Brook. 
Lee, Youngjoo: 2005, 'Exhaustivity as Agreement: The Case of Korean man 'only", Natural Language Semantics 13, 169-200.

Linebarger, Marcia: 1980, The Grammar of Negative Polarity, $\mathrm{PhD}$ dissertation, MIT.

May, Robert: 1985, Logical Form. Its structure and Derivation. MIT Press, Cambridge, Ma.

Rooth, Mats: 1985, Association with Focus, $\mathrm{PhD}$ dissertation, University of Massachussetts, Amherst.

Rooth, Mats: 1992, 'A Theory of Focus Interpretation', Natural Language Semantics 1, 75-116.

Rooth, Mats: 1996, 'Focus', In Lappin (1996), 271-297.

Rooth, Mats: 1999, 'Association with focus or Association with Presupposition?', in P. Bosch and R. van der Sandt (eds.), Focus, 232-244. Cambridge University Press, Cambridge.

Sag, Ivan: 1976, Deletion and Logical Form, PhD dissertation, MIT.

Schwarzschild, Roger: 2004, 'Association with Only, Givenness and Anaphora Resolution'. Talk given at Stuttgart University.

von Stechow, Amim and Dieter Wunderlich (eds.): 1991, Semantik. Ein internationales Handbuch der zeitgenössischen Forschung. (HSK 6). · de Gruyter, Berlin.

Taglicht, Josef: 1984, Message and Emphasis. On focus and scope in English (English Language Series 15). Longman, London and New York.

Tancredi, Christopher: 1990, 'Syntactic Association with Focus', in D. Meyer, S. Tomioka, and L. Zidani-Eroglu (eds.), Proceedings from the First Meeting of the Formal Linguistic Society of Mid-America, University of Wisconsin at Madison, 289-303.

Tancredi, Christopher: 2004, 'Associative Operators', Gengo Kenkyu 125, 31-82.

Wagner, Michael: 2005, Prosody and Recursion, PhD dissertation, MIT.

Wold, Dag: 1996, 'Long-Distance Selective Binding: The Case of Focus', in Proceedings of SALT VI, 311-328. 